5

\title{
Long-term trends in the ionosphere and upper atmosphere parameters
}

\author{
JÜRGEN BREMER $\left({ }^{1}\right)$, LUCILLA ALFONSI $\left({ }^{2}\right)$, PAL BENCZE $\left({ }^{3}\right)$, JAN LAŠTOVIČKA $\left({ }^{4}\right)$, \\ ANDREI V. MIKHAILOV $\left({ }^{5}\right)$ and NEIL ROGERS $\left({ }^{6}\right)$ \\ $\left({ }^{1}\right)$ Leibniz-Institute of Atmospheric Physics, Kühlungsborn, Germany \\ (2) Istituto Nazionale di Geofisica e Vulcanologia, Roma, Italy \\ (') Geodetic and Geophysical Research Institute, Hungarian Academy of Sciences, Sopron, Hungary \\ $\left({ }^{4}\right)$ Institute of Atmospheric Physics, Academy of Sciences of Czech Republic, Prague, Czech Republic \\ $\left(^{5}\right)$ Institute of Terrestrial Magnetism, Ionosphere and Radio Wave Propagation (IZMIRAN), \\ Russian Academy of Sciences, Troitsk (Moscow Region), Russia \\ ${ }^{(}{ }^{6}$ Centre for RF Propagation and Atmospheric Research, QinetiQ, Malvern, U.K.
}

The first part of the paper is directed to the investigation of the practical importance of possible longterm trends in the F2-layer for ionospheric prediction models. Using observations of about 50 different ionosonde stations with more than 30 years data series of $f o F 2$ and $h m F 2$, trends have been derived with the solar sunspot number $R_{12}$ as index of the solar activity. The final result of this trend analysis is that the differences between the trends derived from the data of the individual stations are relatively large, the calculated global mean values of the foF 2 and $h m F 2$ trends, however, are relatively small. Therefore, these small global trends can be neglected for practical purposes and must not be considered in ionospheric prediction models. This conclusion is in agreement with the results of other investigations analyzing data of globally distributed stations. As shown with the data of the ionosonde station Trom$s \emptyset$, however, at individual stations the ionospheric trends may be markedly stronger and lead to essential effects in ionospheric radio propagation. The second part of the paper deals with the reasons for possible trends in the Earth's atmo- and ionosphere as investigated by different methods using characteristic parameters of the ionospheric $D-, E$-, and $F$-regions. Mainly in the $F 2$-region different analyses have been carried out. The derived trends are mainly discussed in connection with an increasing greenhouse effect or by long-term changes in geomagnetic activity. In the F1-layer the derived mean global trend in $f o F 1$ is in good agreement with model predictions of an increasing greenhouse effect. In the $E$-region the derived trends in $f o E$ and $h^{\prime} E$ are compared with model results of an atmospheric greenhouse effect, or explained by geomagnetic effects or other anthropogenic disturbances. The trend results in the $D$-region derived from ionospheric reflection height and absorption measurements in the LF, MF and HF ranges can at least partly be explained by an increasing atmospheric greenhouse effect.

\subsection{INTRODUCTION}

Trend investigations of different ionospheric and atmospheric parameters became more important during recent years as such trends could be caused by anthropogenic activities. In this paper we will concentrate on two main questions:

1) Are there trends in the ionosphere which have to be considered in radio wave prediction models?

2) What are the reasons for possible trends in the Earth's atmosphere and ionosphere? 
The results related to these two topics are presented in Sections 5.2 and 5.3, discussed in Section 5.4 and briefly summarized in Section 5.5.

\subsection{Practical aspects of IONOSPheric TRENDS}

In this section some practical aspects of ionospheric radio propagation are discussed. We restrict our investigations to trends in the ionospheric F2-region using their height and maximum electron density data from different ionosonde stations. In Section 5.2.1 mean global trends are derived, whereas in Section 5.2.2 some practical aspects of the ionospheric radio propagation are presented using data from an individual ionosonde station.

\subsubsection{Derivation of mean global trends}

As is well-known from many investigations the behavior of the ionosphere is markedly controlled by solar activity. In most of the ionospheric prediction models the solar activity is described by the solar sunspot number $R_{12}$. Therefore, in the analyses to investigate the practical aspects of possible ionospheric trends this parameter has been used. As the ionospheric radio propagation in the HF range is mainly dependent on the behavior of the ionospheric F2-region (height and maximum electron density), in the following the results of trend analyses of $h m F 2$ and foF 2 observations all around the world are presented. The analyses have been carried out for data series mainly starting at 1957 with a duration of at least 30 years. Altogether the results of 53 stations with $f o F 2$ data and 50 stations with $h m F 2$ data have been investigated. The $h m F 2$ values were derived from $M(3000) F 2$ data using the simple formula of Shimazaki (1955). The trend method used starts with calculations of simple regression equations using monthly mean values the ionospheric parameter $X(=h m F 2$ or $f o F 2)$ at each full hour in dependence on the solar activity assuming a linear dependence

or a quadratic equation

$$
X_{\mathrm{th}}=a+b \cdot R_{12}
$$

$$
X_{\mathrm{th}}=a+b \cdot R_{12}+c \cdot R_{12}^{2} .
$$

Then the differences between the observed $X_{\mathrm{obs}}$ and the calculated values $X_{\text {th }}$ are estimated

$$
\Delta X=X_{\mathrm{obs}}-X_{\mathrm{th}}
$$

or relative differences are calculated

$$
\Delta X=\left(X_{\mathrm{obs}}-X_{\mathrm{th}}\right) / X_{\mathrm{th}} .
$$

Using mean yearly $\Delta X$ values derived by averaging the monthly $\Delta X$ values at each full hour (averages of $12 \times 24$ data series), mean linear tends have been estimated according to

$$
\Delta X=d+e \cdot \text { year. }
$$

In fig. 5.1a,b two histograms are shown for the trend results of $f o F 2$ observations at 53 different ionosonde stations. In the upper part the solar activity has been eliminated by a linear relation according to eq. (5.1a), in the lower part by the quadratic relation according to eq. (5.1b). In both cases differences according to eq. (5.2a) have been used in the trend estimations. The distributions of the 

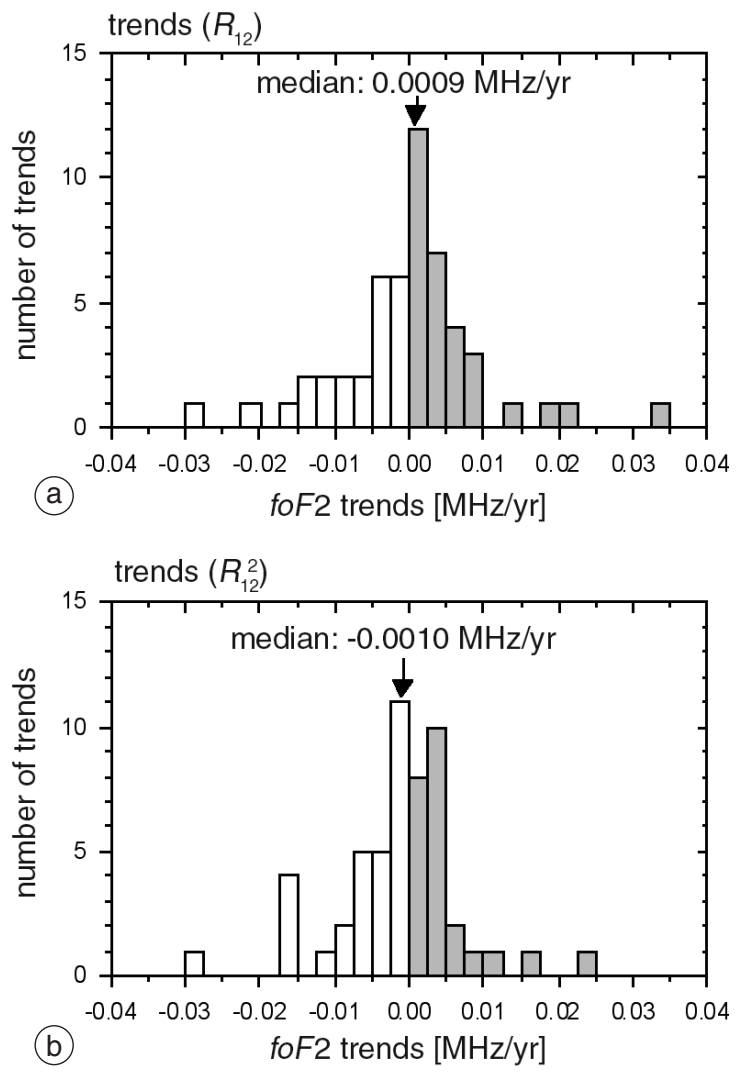

Fig. 5.1a,b. Histograms of 53 individual $f o F 2$ trends derived after a linear (a) and quadratic (b) elimination of the solar influence. The corresponding median values are marked by arrows.

individual foF 2 trends are relatively broad, the median trends however are relatively near to zero. As to be expected both data sets are well correlated with a correlation coefficient $r=0.92$.

In fig. 5.2a,b the trend results of $h m F 2$ observations at 50 different stations are shown in a similar way as for foF 2 in fig. 5.1a,b. Also here relatively broad distributions of the individual trends can be seen, whereas the median values are again very near to zero. The correlation between both trend ensembles is very good with $r=0.995$.

In table 5.I the mean trends of $f o F 2$ and $h m F 2$ (median as well as mean values) have been compiled. These data can partly be found in figs. 5.1a,b and 5.2a,b and from trend results using a linear solar activity influence (eq. (5.1a)) and relative differences $\Delta X$ (eq. (5.2b)) not shown before. For the mean trends the error values with a significance level of $95 \%$ are also presented (for calculation see Taubenheim, 1969). All mean trends are smaller than the corresponding error limits, indicating that the mean trends are not significantly different from zero. Nevertheless from all mean and median values in table 5.I the expected changes for $\triangle f o F 2$ and $\triangle h m F 2$ have been estimated for a time period of 100 years. As to be seen these values are very much smaller compared with changes induced by the variable solar activity. Therefore, possible long-term changes have not to be introduced in ionospheric prediction models. Until now global mean trends in $f o F 2$ and $h m F 2$ have no essential practical meaning. 

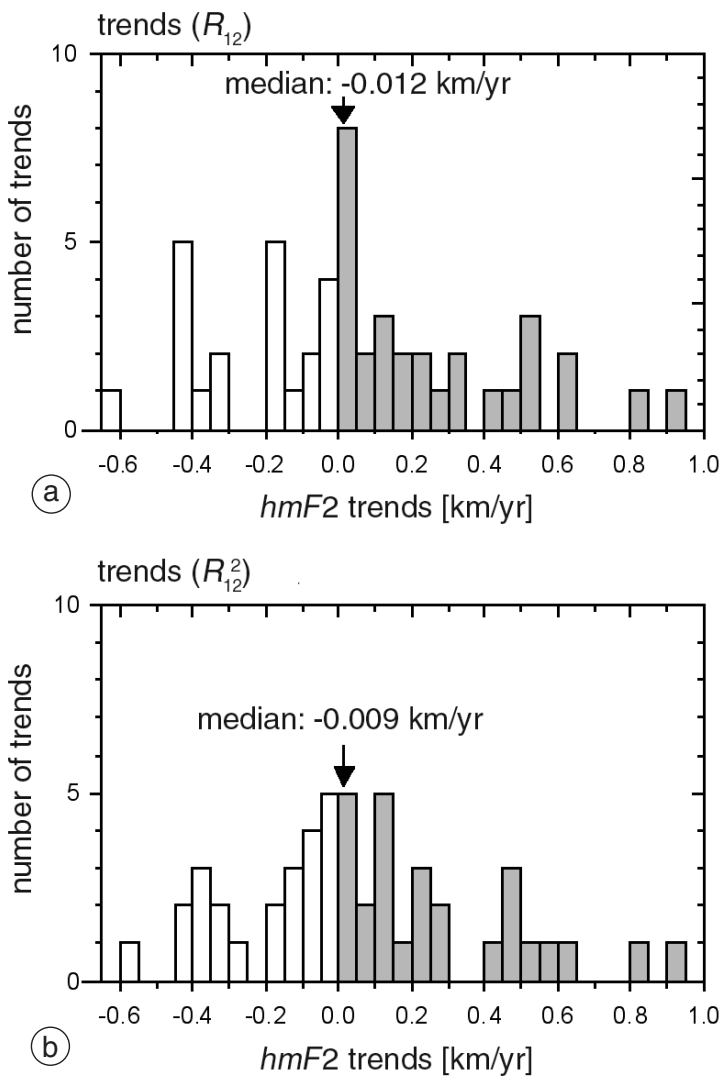

Fig. 5.2a,b. Histograms of 50 individual $h m F 2$ trends derived after a linear (a) and quadratic (b) elimination of the solar influence. The corresponding median values are marked by arrows.

Table 5.I. Mean trends of $f o F 2$ and $h m F 2$ derived from observations at about 50 ionosonde stations (beginning 1957 , more than 30 years) by different methods. $\triangle f o F 2$ and $\triangle h m F 2$ are the expected changes of $f o F 2$ and $h m F 2$ during 100 years.

\begin{tabular}{|c|c|c|c|c|}
\hline & & Trend $\left(R_{12}\right)$ & Trend $\left(R_{12}^{2}\right)$ & Trend $\left(R_{12}\right)$ rel \\
\hline$f o F 2$ & $\begin{array}{l}\text { Mean trend } \\
95 \% \text { error } \\
\Delta \text { foF } 2 \text { mean } \\
\text { Median trend } \\
\Delta \text { foF } 2 \text { med }[\mathbf{M H z}]\end{array}$ & $\begin{array}{l}+0.0003 \mathrm{MHz} / \mathrm{yr} \\
\pm 0.0027 \mathrm{MHz} / \mathrm{yr} \\
+\mathbf{0 . 0 3} \mathbf{M H z} \\
+0.0009 \mathrm{MHz} / \mathrm{yr} \\
+\mathbf{0 . 0 9} \mathbf{M H z}\end{array}$ & $\begin{array}{l}-0.0013 \mathrm{MHz} / \mathrm{yr} \\
\pm 0.0023 \mathrm{MHz} / \mathrm{yr} \\
\text { - } \mathbf{0 . 1 3} \mathbf{M H z} \\
-0.0010 \mathrm{MHz} / \mathrm{yr} \\
\mathbf{- 0 . 1 0} \mathbf{M H z}\end{array}$ & $\begin{array}{l}-0.016 \% / \mathrm{yr} \\
\pm 0.041 \% / \mathrm{yr} \\
-\mathbf{0 . 1 3} \mathbf{M H z} \\
+0.001 \% / \mathrm{yr} \\
+\mathbf{0 . 0 0 8} \mathbf{M H z}\end{array}$ \\
\hline$h m F 2$ & $\begin{array}{l}\text { Mean trend } \\
\text { 95\% error } \\
\mathbf{\Delta h m F 2 m e a n ~} \\
\text { Median trend } \\
\boldsymbol{\Delta h} \boldsymbol{m} \boldsymbol{F} \mathbf{2 m e d}[\mathbf{k m}]\end{array}$ & $\begin{array}{l}+0.058 \mathrm{~km} / \mathrm{yr} \\
\pm 0.096 \mathrm{~km} / \mathrm{yr} \\
+\mathbf{5 . 8} \mathbf{~ k m} \\
+0.012 \mathrm{~km} / \mathrm{yr} \\
+\mathbf{1 . 2} \mathbf{~ k m}\end{array}$ & $\begin{array}{l}+0.063 \mathrm{~km} / \mathrm{yr} \\
\pm 0.092 \mathrm{~km} / \mathrm{yr} \\
+\mathbf{6 . 3} \mathbf{~ k m} \\
+0.009 \mathrm{~km} / \mathrm{yr} \\
+\mathbf{0 . 9} \mathbf{~ k m}\end{array}$ & $\begin{array}{l}+0.021 \% / \mathrm{yr} \\
\pm 0.030 \% / \mathrm{yr} \\
+\mathbf{6 . 3} \mathbf{k m} \\
+0.004 \% / \mathrm{yr} \\
+\mathbf{1 . 2} \mathbf{~ k m}\end{array}$ \\
\hline
\end{tabular}




\subsubsection{Trends at an individual station}

The ionosonde at Troms $\varnothing$ in Northern Norway $\left(69^{\circ} \mathrm{N}, 19^{\circ} \mathrm{E}\right)$ (Hall and Hansen, 2003) is a unique resource providing continuous observations of ionospheric critical frequencies since 1935 and layer heights since 1952. Hall and Cannon $(2001,2002)$ have examined long-term trends in $F$-region parameters at Troms $\varnothing$ using a method similar to that developed by Bremer (1992) and used in Section 5.3.1 below, eq. (5.4). Using daily ionosonde measurements taken at or near noon, linear components of the background variations in $R_{12}$ and geomagnetic index $(A p)$ are subtracted to leave a residual trend. Based on a recently extended set of ionograms, the peak height of the $F 2$ layer, $h m F 2$ is found to fall at $-0.106 \pm 0.087 \mathrm{~km}$ per year and its critical frequency, foF 2 falls at $-0.013 \pm 0.002 \mathrm{MHz}$ per year, where the errors indicate one standard deviation. Ulich et al. (2003) presented an $h m F 2$ data set for a nearby ionosonde at Sodankylä, Finland for the period $1958-2003$ with a trend of $-0.41 \pm 0.04 \mathrm{~km}$ per year - a significantly steeper trend than that seen in the Troms $\varnothing$ data.

Modeling of ionospheric radio system performance requires a propagation tool that contains a three-dimensional map of ionospheric electron density. This may be used to find the skip zones of High Frequency (HF) radio transmissions, or the group delay, phase advance, etc., in transionospheric systems. Parameterized «monthly median» models are often employed, and these use worldwide maps of foF 2 and $h m F 2$ and similar parameters, often referred to as CCIR coefficients (CCIR, 1966; Jones et al., 1969) or URSI coefficients (Rush et al., 1989). The former were based on ionosonde data for the years 1954-1958 and 1964 only and foF2 was described by a set of special mapping functions. The worldwide RMS error in $f o F 2$ is $\sim 0.5 \mathrm{MHz}$. The URSI coefficients are derived from a much larger database of 45000 station-months and include data from 19751979. URSI coefficients showed improved accuracy over the oceans but at the expense of accuracy over land, so that overall the CCIR and URSI maps are of similar accuracy (Bilitza, 2002).

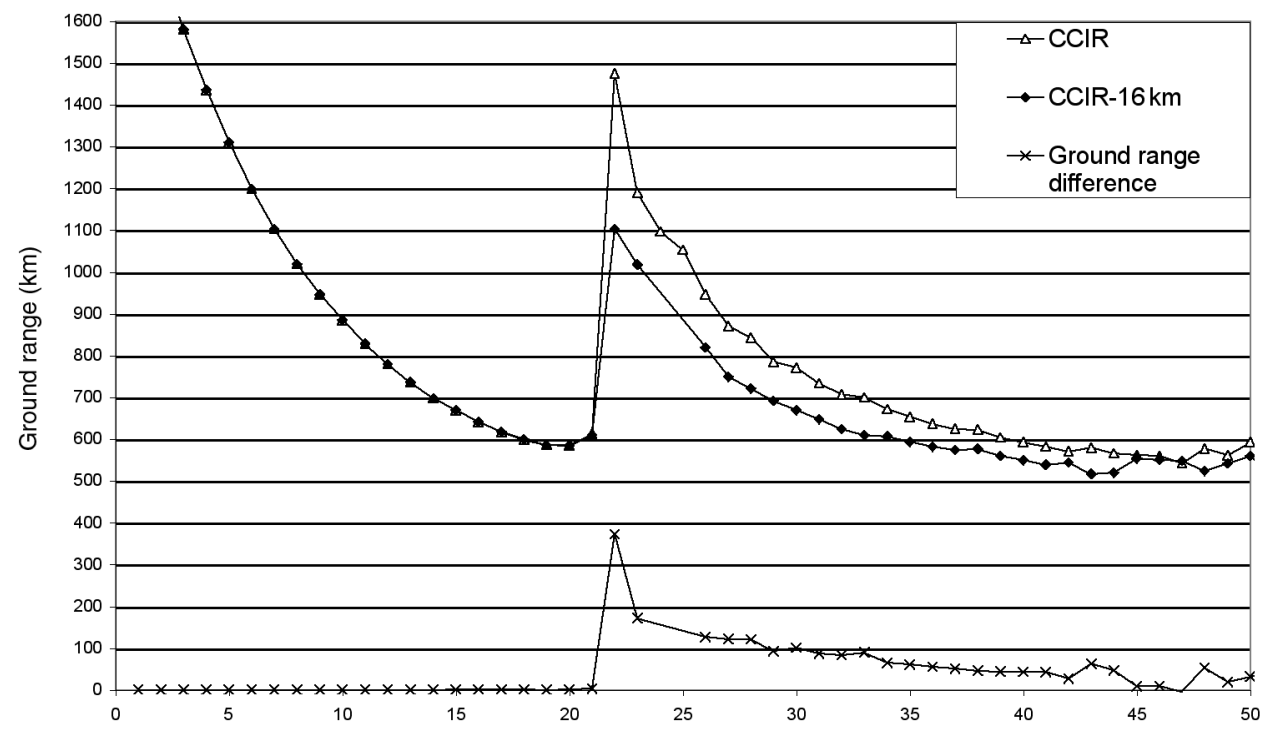

Fig. 5.3. Impact of $16 \mathrm{~km}$ reduction in $h m F 2$ on ground ranges for propagation due south of Troms $\varnothing$ at $8 \mathrm{MHz}$ for December, $12 \mathrm{UT}, R_{12}=50$. 
Five decades have elapsed since the data were collected to generate the CCIR coefficients, and in that time the $F 2$-region over Troms $\emptyset$ has fallen by $5.3 \mathrm{~km}$. Further, $f o F 2$ has decreased by 0.65 $\mathrm{MHz}$, an amount already bigger than the RMS model error of the CCIR model. The impact on HF systems has been assessed by ray tracing through two sets of analytical Dudeney profiles of electron density (Dudeney, 1983). The first set of profiles was fit to the CCIR coefficients and the second was modified to reduce the peak height by $16 \mathrm{~km}$. Based on the analyses of Troms $\varnothing$ ionograms a $16 \mathrm{~km}$ drop in $h m F 2$ is appropriate to the conditions in the year 2100 (provided there is no change in the long-term trends). If we had chosen to use the results of Ulich et al. (2003) then a $16 \mathrm{~km}$ height reduction was appropriate to the year 1990! For a $16 \mathrm{~km}$ drop it was found that ground range errors of $\sim 100 \mathrm{~km}$ per hop will be common if system designers and operators continue to employ the old CCIR maps. A sample of the ray tracing results is presented in fig. 5.3, representing $8 \mathrm{MHz}$ 1-hop propagation south of Troms $\varnothing$ near noon on a December day. Overall, the ground range errors (lower curve) are $50-150 \mathrm{~km}$ for the $1 F 2$ mode of propagation (above $21^{\circ}$ elevation), with greater errors at elevations just above that at which the $E$-layer is penetrated.

These results demonstrate that for trends derived at individual stations their influence on ionospheric radio propagation could be much stronger than for global mean trends. This result could be expected from the broad trend histograms shown in figs. 5.1a,b and 5.2a,b.

\subsection{SCIENTIFIC ASPECTS OF IONOSPHERIC TRENDS}

This section presents the trend results which were derived by different European groups using partly different methods. The results are separately discussed for the different ionospheric regions.

\subsubsection{Trends in the $F 2$-region}

Using a similar analysis method as described in Section 5.2.1 Bremer $(1998,2001)$ investigated data series of more than 100 ionosonde stations. For the elimination of the solar and geomagnetically induced parts, however, the following twofold regression equation was used:

$$
X_{\mathrm{th}}=a+b \cdot R+c \cdot A p
$$

with the solar sunspot number $R$ and the geomagnetic activity index Ap. Also other solar indices have been tested $\left(F_{10.7}, E_{10.7}, R_{12}\right)$, but the derived trends are not markedly influenced by this choice (Bremer, 2001). In fig. 5.4 the updated histograms with the individual trends of $f o F 2$ and $h m F 2$ are presented together with the corresponding median values. As in the investigations discussed in Section 5.2.1, the distributions of the individual trends for both parameters are relatively broad, and the median values are very small. As shown in table 5.II the mean trends of foF 2 and $h m F 2$ are not statistically significant different from zero as follow from the corresponding mean errors.

In fig. 5.5 the individual $h m F 2$-trends are presented in dependence on longitude and latitude. Negative trends are marked by blue, positive trends by red symbols. Significant trends with a $95 \%$ reliability level are characterised by full dots, non significant trends by circles. There is no clear dependence of the trends on latitude or longitude, but there seem to be some regional differences. Whereas in the western part of Europe most trends are negative, in Central Asia the trends are more positive. The causes of these regional differences are not known.

Similar trend analyses have been made by Ulich and Turunen (1997a) at first with $h m F 2$ data of Sodankylä and later for more than 50 stations (Ulich and Turunen, 1997b). These authors also found similar regional differences in the $h m F 2$ trends as shown in fig. 5.5. Ulich (2000) also investigated 

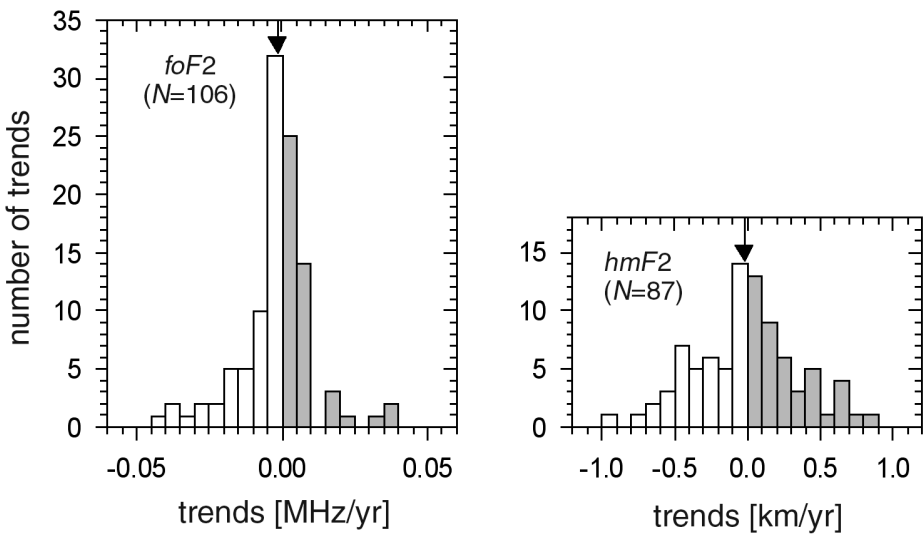

Fig. 5.4. Histograms for $f o F 2$ and $h m F 2$ trends derived from ionosonde observation at different stations. Number of stations are given in brackets.

Table 5.II. Mean experimental trends and error limits (95\%) derived from trend analyses of different ionosonde parameters at different stations. Significant mean trends are bold-faced.

\begin{tabular}{|c|c|c|c|c|}
\hline & Parameter & $\mathrm{N}$ & Mean trend & Error $(95 \%)$ \\
\hline F2-region & $\begin{array}{l}f o F 2 \\
h m F 2\end{array}$ & $\begin{array}{c}106 \\
87\end{array}$ & $\begin{array}{c}-0.0018 \mathrm{MHz} / \mathrm{yr} \\
-0.009 \mathrm{~km} / \mathrm{yr}\end{array}$ & $\begin{array}{c} \pm 0.0025 \mathrm{MHz} / \mathrm{yr} \\
\pm 0.076 \mathrm{~km} / \mathrm{yr}\end{array}$ \\
\hline$F 1$-region & foF 1 & 51 & $0.0027 \mathrm{MHz} / \mathrm{yr}$ & $\pm 0.0011 \mathrm{MHz} / \mathrm{yr}$ \\
\hline$E$-region & $\begin{array}{l}f o E \\
h^{\prime} E\end{array}$ & $\begin{array}{l}72 \\
31\end{array}$ & $\begin{array}{c}\mathbf{0 . 0 0 1 4} \mathbf{M H z} / \mathbf{y r} \\
-0.040 \mathrm{~km} / \mathrm{yr}\end{array}$ & $\begin{array}{c} \pm \mathbf{0 . 0 0 0 7} \mathbf{~ M H z} / \mathbf{y r} \\
\pm 0.070 \mathrm{~km} / \mathrm{yr}\end{array}$ \\
\hline
\end{tabular}

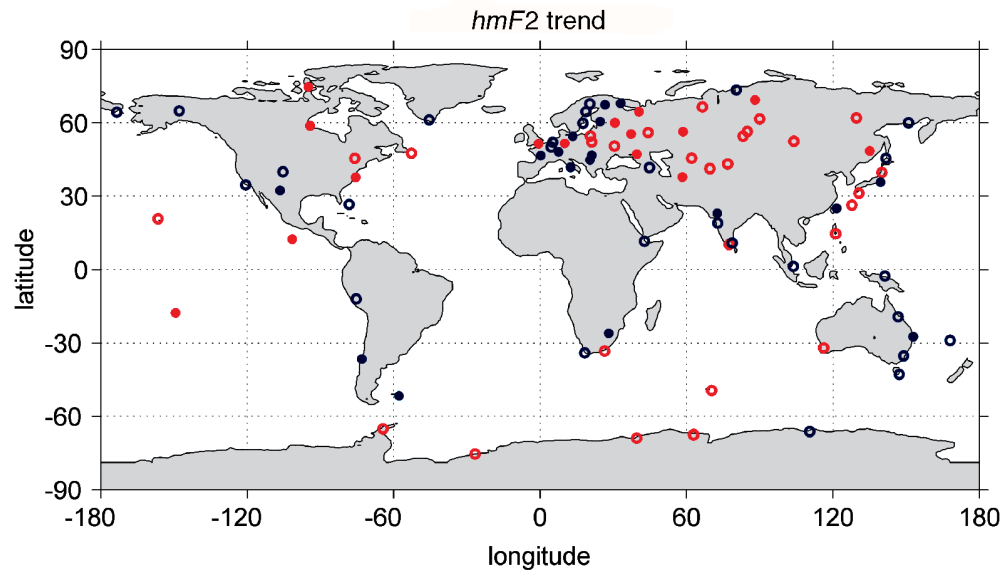

Fig. 5.5. Trends of $h m F 2$ in dependence on latitude and longitude derived from data sets of 87 different ionosonde stations. Negative trends are blue, positive are red, significant trends are marked by full dots, non significant trends by circles. 
different formulas to derive $h m F 2$ from ionosonde $M(3000) F 2$ data. He found quantitative differences in the derived trends depending on the $h m F 2$ formula used. This finding is caused by the fact that the ionisation below the F2-layer is differently considered by the different formulas. Therefore, trends in the underlying ionisation parameters my also cause differences in the $h m F 2$ trends.

Bencze et al. (1998) derived trends in $h m F 2$ for some Asian and American stations using the same method as Bremer (2001) and Ulich and Turunen (1997a,b). He also found similar regional differences with more negative trends at coastal regions and more positive trends inside the continents.

Alfonsi et al. (2001, 2002a) derived foF 2 trends for different stations at high and middle latitudes using monthly mean values as well as hourly values. In their analyses only such experimental data have been introduced which are not accompanied by qualification letters to reduce the uncertainty of the hourly foF 2 values. The investigation of the ionospheric long-term changes follows an analytical approach similar to that shown in eq. (5.4). The original contribution comes from the use of $A p(\tau)$ and MACAp $(\tau)$, used for investigating the geomagnetic control on the ionospheric trends. $A p(\tau)$ and $\operatorname{MACAp}(\tau)$ have been introduced for representing the non-linear relationship between geomagnetic activity and ionospheric behaviour (Wrenn, 1987; Perrone and De Franceschi, 1999). In particular, $A p(\tau)$ is a time-weighted accumulation of $A p$ index, and MACAp $(\tau)$ is the related catalogue, introduced for characterising four levels of geomagnetic impact on the ionosphere ranging from 0 (quiet magnetic condition) to 3 (severely disturbed magnetic condition) (De Franceschi et al., 1999, 2002). Extracting from long data series of hourly foF 2 data those values recorded under magnetically quiet conditions (MACAp $(\tau)=0)$, Alfonsi et al. $(2002 \mathrm{a}, \mathrm{b})$ found a long-term decrease of the $F 2$ plasma frequency. All foF 2 trends derived from data of four different stations shown in fig. 5.6 are negative with a median value of $-0.0035 \mathrm{MHz} / \mathrm{yr}$.

A totally different method for derivation of trends has been developed by Mikhailov and Marin (2000, 2001) and Marin et al. (2001). They use 12-monthly running hourly mean values of foF 2 or $h m F 2$ and of the solar sunspot number $\left(R_{12}\right)$ and geomagnetic activity $\left(A p_{12}\right)$. For $f o F 2$ only data during three years near solar minimum and maximum are taken into consideration to avoid the hysteresis effect whereas for $h m F 2$ data of all years have been analysed. Data gaps are filled by the MQMF2 model (Mikhailov et al., 1996). The regression model used is a modification of eq. (5.1b) according to

$$
X_{t h}=a+b \cdot R_{12}+c \cdot R_{12}^{2}+d \cdot R_{12}^{2}+\left(e \cdot A p_{12}\right) .
$$

The analyses have been made with or without the geomagnetic term. Relative deviations of the observed data have been used according to eq. (5.2b). The main results can be summarized:

1) The influence of the geomagnetic activity can only partly be removed also if $A p_{12}$ is introduced in eq. (5.5).

2) Periods with increasing and decreasing geomagnetic activity are related to different ionospheric trends: $f_{o} F 2$ trends are in anti-phase, $h m F 2$ trends in-phase with $A p$ trends. This behavior can be seen in fig. 5.7 for long-term observations at the station Slough.

3) The diurnal and latitudinal variations of the $f o F 2$ and $h m F 2$ trends can be explained by the current geomagnetic storm behavior. Therefore, this method is called geomagnetic control concept by their authors.

Danilov $(2002,2003)$ developed a method to eliminate the long-term changes in geomagnetic activity in $f o F 2$ trends. Starting with relative $\triangle f o F 2$ values, calculated in a similar way as by Mikhailov and Marin (2000) but using data of all available years, he assumes that the derived foF2-trend $k$ (obs) is the result of a linear combination of a non-geomagnetic trend $k(\operatorname{tr})$ and a geomagnetically caused trend. He further assumes that the geomagnetic activity is described by annual mean values of $A p$ and the geomagnetic trend is proportional to the gradient of $A p, k(A p)$

$$
k(\mathrm{tr})=k(\mathrm{obs})+a_{1} \cdot k(\mathrm{Ap}) .
$$




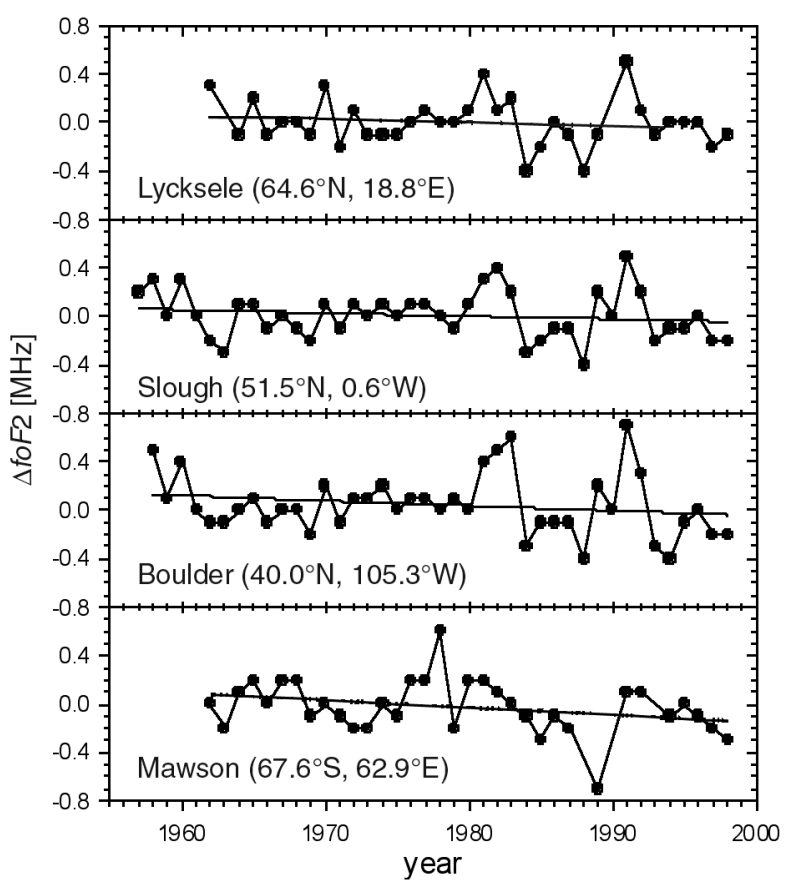

Fig. 5.6. Long-term trends of $f o F 2$ from different stations under magnetically quiet condition $(\mathrm{MACA} p(\tau)=0)$ and after removal of the solar cycle influence.

Here $a_{1}$ is a scaling coefficient which includes the efficiency of the geomagnetic activity impact on foF 2 and may therefore be different for different stations and local times. The details of the method to estimate the $a_{1}$ values can be found in Danilov (2002, 2003). Using foF 2 data of 23 stations with observations of more than 35 years a mean non-geomagnetic trend of $-0.012 \mathrm{MHz} / \mathrm{yr}$ was found for the period between 1958 and the mid-nineties and $-0.0075 \mathrm{MHz} / \mathrm{yr}$ for an earlier interval between 1948-1985 (here only data of 8 stations were available).

Another attempt to eliminate the geomagnetic influence on the $f o F 2$ trends has been tried by Mikhailov et al. (2002). They start their analysis with monthly regressions according to eq. (5.1a), estimate relative deviations after eq. (5.2b) and calculate 11-year running mean values from these deviations: $\delta f \circ 2_{132}$. The geomagnetic activity effect in $\delta f o F 2_{132}$ is derived from 11 -year running mean values $A p_{132}$ by

$$
\delta f o F 2_{132 \mathrm{th}}=b_{0}+b_{1} \cdot A p_{132}(t+n)+b_{2} \cdot A p_{132}^{2}(t+n)
$$

where $n$ is the time shift in years of $A p_{132}$ with respect to $\delta f o F 2_{132}$ variations. From the residuals

$$
\delta f o F 2=\delta f o F 2_{132 \mathrm{obs}}-\delta f o F 2_{132 \mathrm{th}}
$$

linear trends according to eq. (5.3) have been calculated with the following main results:

1) The derived foF 2 trends are nearly independent of latitude and of the phase of long-term changes in geomagnetic activity (basic point of geomagnetic control concept of Mikhailov and Marin, 2000, 2001). 
2) Most of the residual trends are negative, often however not significant. In fig. 5.8 a significant negative trend is shown using the long-term data series observed at Slough.

Summarizing it can be stated that in all analyses with data of different stations the derived mean trends in the F2-region are relatively small and not important for practical applications. At individual stations (Ulich and Turunen, 1997a; Rogers et al., 2002), however, the trends can be markedly more pronounced, resulting in broad global histograms as shown in fig. 5.4.
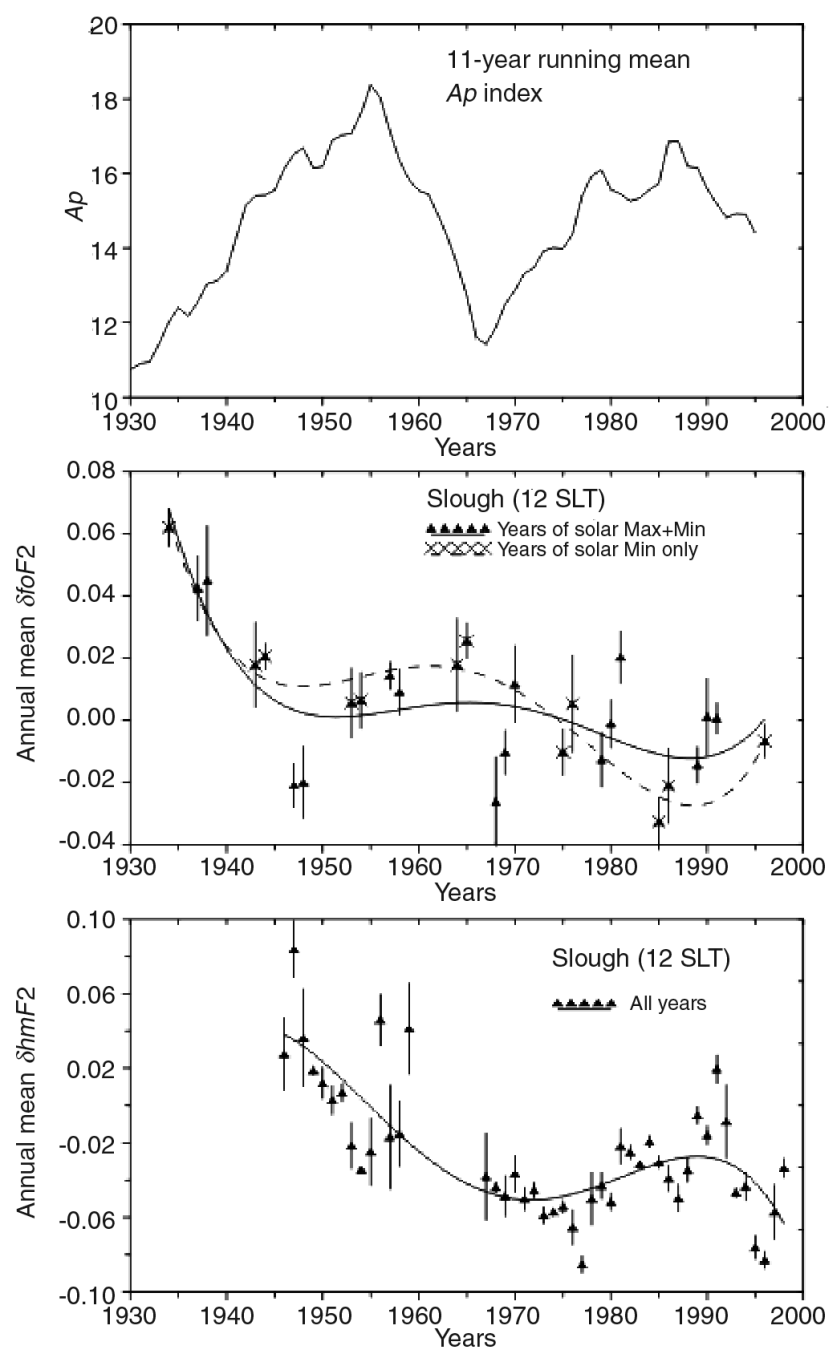

Fig. 5.7. (Top) Long-term variation of geomagnetic activity (11-year running mean of $A p$ ) together with relative deviations of foF 2 (middle) and of $h m F 2$ (bottom) derived from ionosonde observations at Slough. 


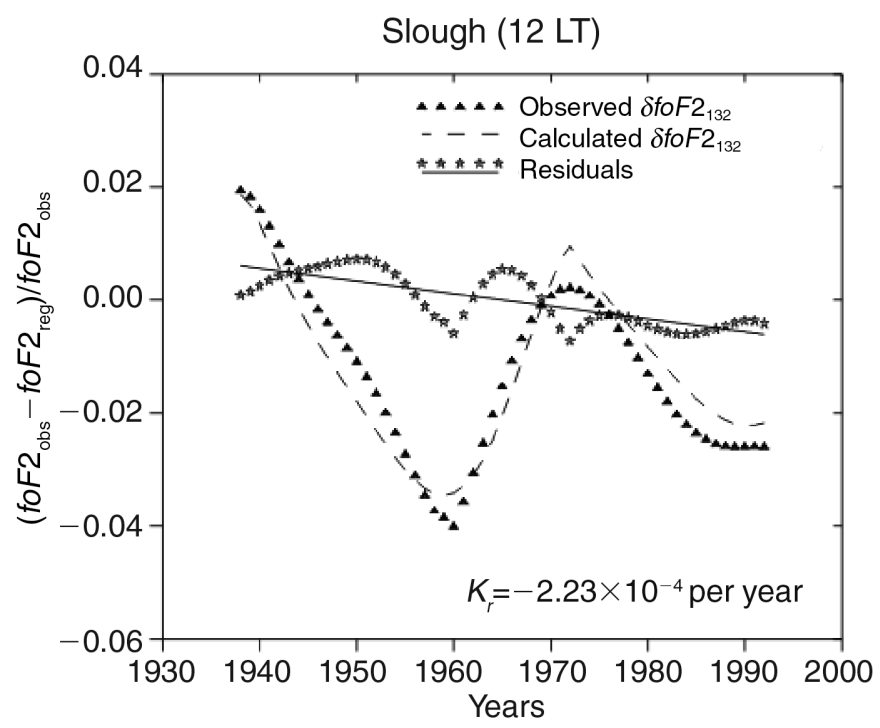

Fig. 5.8. Relative deviations of $f o F 2$ after very long-term ionosonde observations at the station Slough (full line: linear trend; $K r$ : trend parameter).

\subsubsection{Trends in the $F 1$-region}

Trends in $f_{o F} 1$ data series were derived by Bremer (2001) using observations at 51 different ionosonde stations. For the elimination of the solar and geomagnetically induced parts the twofold regression eq. (5.4) was used. In fig. 5.9 the histogram of the updated individual trends is shown together with the global median value (marked by an arrow). The distribution is asymmetric to zero as slightly seen by essentially more positive (grey) than negative trends (white). The estimated mean trend with $0.0027 \mathrm{MHz} / \mathrm{yr}$ is significantly different from zero as seen in table 5.II where the corresponding mean error can also be found. Therefore this trend has been marked there by bold letters.

\subsubsection{Trends in the $E$-region}

Trends in the ionospheric $E$-region were estimated by Bremer (2001) from $h^{\prime} E$ and $f o E$ observations at different ionosonde stations. For the elimination of the solar and geomagnetically induced parts the twofold regression eq. (5.4) has been used. The results of the trend analyses are shown by histograms together with their global median values (marked by arrows) in fig. 5.10. The estimated mean $f o E$ trend is significant with a reliability level of more than $95 \%$, whereas the mean $h^{\prime} E$ trend is not significant different from zero. This can be seen in table 5.II where the mean values and their mean errors are presented.

Mikhailov and de la Morena (2003) investigated $f o E$ trends from different ionosonde stations with their revised trend method which was developed for foF2-trend investigations (Mikhailov et al., 2002). This method is briefly described above. Instead of eq. (5.8), they used a slightly modified equation

$$
\delta f o E_{132 \mathrm{th}}=b_{0}+b_{1} \cdot A p_{132}^{\beta}(t+n)
$$




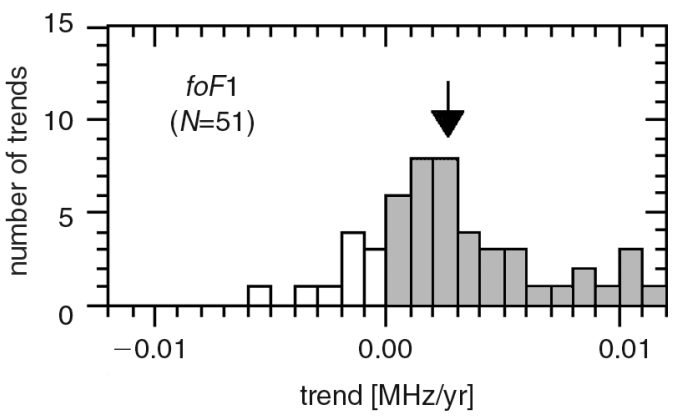

Fig. 5.9. Histogram for $f o F 1$ trends derived from ionosonde observations at different stations. Number of stations is given in brackets.
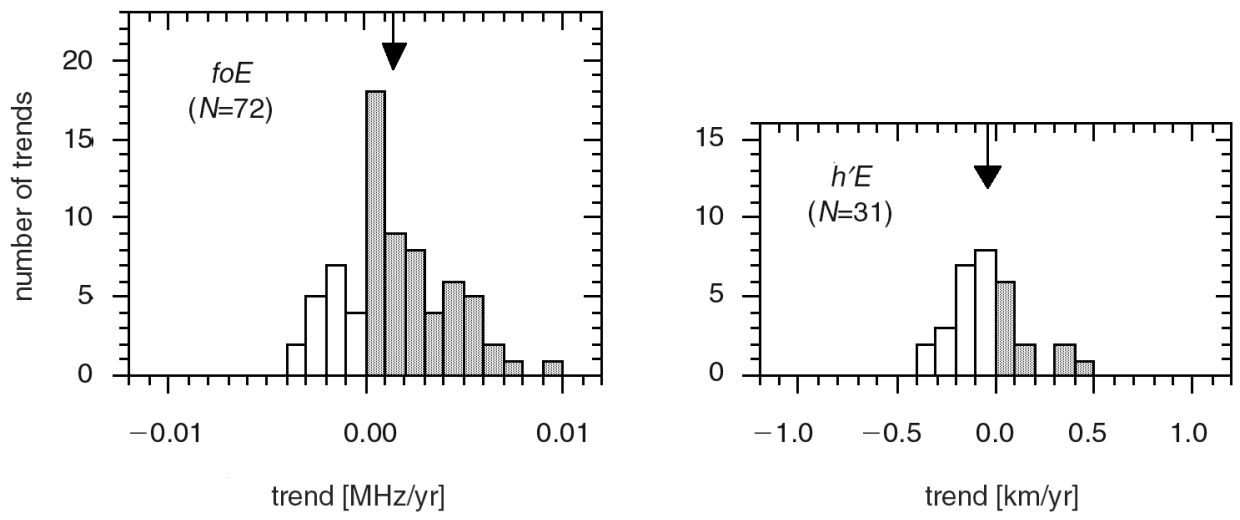

Fig. 5.10. Histogram for $f o E$ and $h^{\prime} E$ trends derived from ionosonde observations at different stations. Numbers of stations are given in brackets.

where $\beta$ is a fitting parameter and $\mathrm{n}$ again the time shift in years of $A p_{132}$ with respect to $\delta f o E_{132}$. Their main results are:

1) Before about $1970 \delta f o E_{132}$ and $A p_{132}$ are negatively correlated. The authors call it «natural $f o E$ variation».

2) After about 1970 positive $f o E$ trends were detected which could anthropogenically be caused.

In fig. 5.11 an example is shown of the dependence between $\delta f o E_{132}$ and $A p_{132}$ using ionosonde data observed at the station Rome.

\subsubsection{Trends in the $D$-region}

In the ionospheric $D$-region the available data series for trend analyses are limited, therefore we restricted these investigations to some reflection height and ionospheric absorption data observations. 


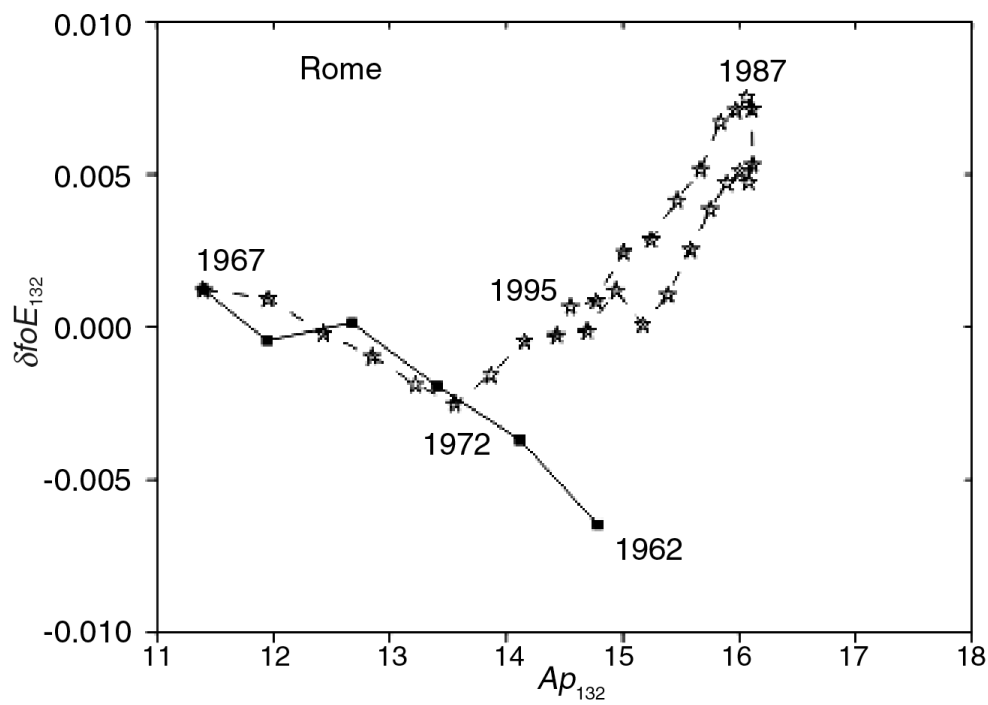

Fig. 5.11. Variation of $\delta f o E_{132}$ in dependence on $A p_{132}$ for $f o E$ data series observed at the station Rome with the marked increase after 1972.

From the interference field between the ionospherically reflected sky wave and the ground wave of a far distant radio transmitter it is possible to derive ionospheric reflection heights (often called phase heights, for details of the method see Bremer and Berger, 2002, and references therein). From long-term field strength observations of a measuring path at $162 \mathrm{kHz}$ in mid-latitudes trends of the reflection height have been derived for a constant solar zenith angle $\chi=78.4^{\circ}$. In fig. 5.12 the yearly trend can be seen. Here the solar and geomagnetically induced variations have been removed according to eq. (5.4) using the solar Lyman $\alpha$ radiation instead of the solar sunspot number $R$. A significant negative trend could be derived with about $-0.028 \mathrm{~km} / \mathrm{yr}$.

Such a shrinking of the lower ionosphere could also be detected from observations of reflection heights at ionospheric drift measurements during night-time (Kürschner and Jacobi, 2002). These measurements were made in the LF range $(177 \mathrm{kHz})$ at short distance between transmitter and receiver $(170 \mathrm{~km})$.

Both mean trends of reflection heights near $82 \mathrm{~km}$ (LF phase heights) and near $95 \mathrm{~km}$ (drift measurements) as well as the trends in the $E$-layer peak height near $100-110 \mathrm{~km}\left(h^{\prime} E\right.$-trends in Section 5.3.3) have negative values which may slightly increase with increasing height. The significance level of the phase height trend is high (mostly higher than 99\%), for the two other methods this level is however lower due to the shorter data series (drift method) or due to marked differences between individual stations (ionosonde data, see the broad histogram in fig. 5.10 and the derived mean trend and error values in table 5.II).

Ionospheric absorption data have been analysed for three different reflection height ranges, below about $80 \mathrm{~km}$, between about 80-90 km, and above about $90 \mathrm{~km}$ (Bremer and Laštovička, 2002; Laštovička and Bremer, 2004).

From long-term observations of the absorption of a very long measuring path at $164 \mathrm{kHz}$ (distance between transmitter and receiver: $1720 \mathrm{~km}$ ) during summer and noon conditions (Nestorov et al., 1991, and updated later by Laštovička and Pancheva, 1999) a clear positive trend could be detected. The reflection height of this measuring path is clearly below $80 \mathrm{~km}$. 


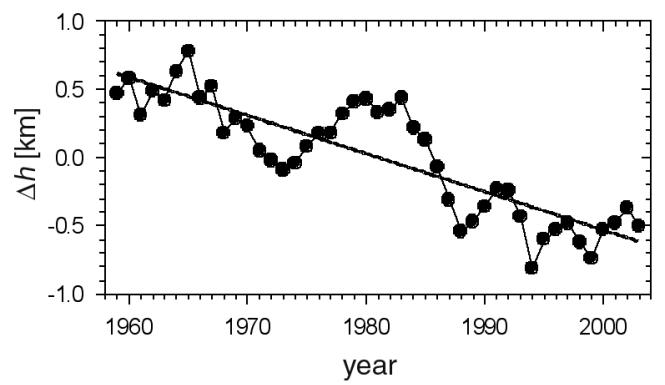

Fig. 5.12. Long-term variation of yearly mean phase-heights at mid-latitudes $\left(162 \mathrm{kHz}, \chi=78.4^{\circ}\right)$ after elimination of the solar and geomagnetically induced variations.

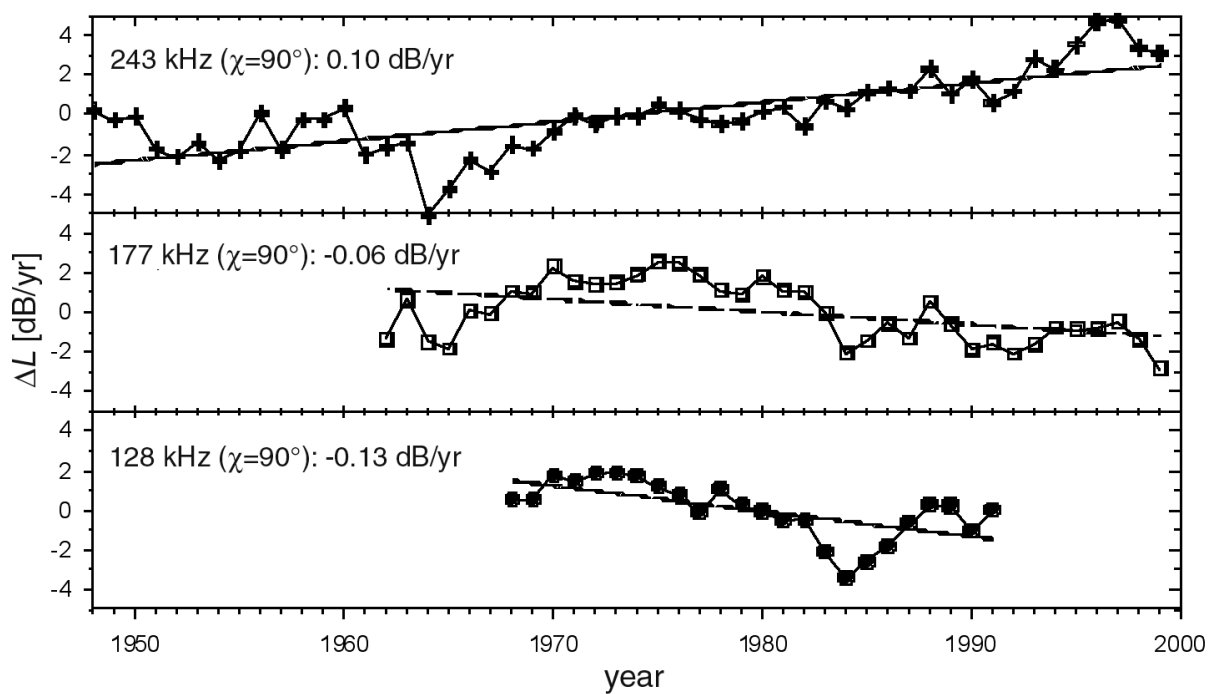

Fig. 5.13. Trends of ionospheric absorption for three measuring paths with different frequencies at a constant solar zenith angle $\chi=90^{\circ}$ after elimination of the solar and geomagnetically induced parts.

Using, however, data from LF absorption measurements at short distances (about 180-220 km) the derived trends change their general behavior. In fig. 5.13 the absorption trends are shown for three different frequencies at the same solar zenith angle $\chi=90^{\circ}$. Whereas the trend the lowest frequency is negative, the trend increases with increasing frequency and becomes even positive at the highest frequency. That means that with increasing reflection height the trends become more positive. We observe the same behavior if trends have been estimated for the same measuring path but at different solar zenith angles (example can be found in Bremer, 2003). With increasing solar zenith angle the trends becomes again more positive.

Investigating ionospheric absorption measurements in the MF and $\mathrm{HF}$ ranges at oblique incidence (distances between transmitter and receiver are about $170 \mathrm{~km}$ up to $550 \mathrm{~km}$ ) only positive trends have 
been estimated. Some examples can be seen in Laštovička $(2001,2002)$ and Bremer and Laštovička (2002). The reflection heights of these measuring paths are above $90 \mathrm{~km}$. The tendency detected at the LF absorption data series that with increasing reflection height the trends become positive, is therefore confirmed by the absorption measurements in the MF and HF ranges.

\subsection{Discussion}

Two main problems will be discussed here concerning a) the practical importance of ionospheric trends and b) the scientific reasons for possible trends in the different regions of the ionosphere.

\subsubsection{Practical aspects}

Ionospheric HF propagation is mainly influenced by the behaviour of the $F 2$-region expressed by their characteristic parameters foF2 and $h m F 2$. As shown in Section 5.2.1 and summarised in table 5.I, possible global trends of both parameters are very small. This finding is in agreement with other investigations presented in Section 5.3.1 where the results of more complex trend analyses are shown using observations from all over the world. Therefore, in global ionospheric prediction models it is not necessary to include the effect of ionospheric long-term changes. The solar and geomagnetically induced variations are markedly more important.

At individual stations, however, the trends can be essentially more pronounced. This can be seen in the relatively broad histograms of the $f o F 2$-trends in fig. 5.1a,b and of $h m F 2$-trends in fig. 5.2a,b. The trend values of the stations Troms $\varnothing$ and Sodankylä used in Section 5.2.2 to investigate their impact on ionospheric radio propagation are well inside the corresponding histograms. Unfortunately we do not know the reasons for the strong differences of the trends derived at individual stations. One reason for such differences between the trends at (partly neighbouring) stations could be artificial steps in the data series caused by technical changes at the ionosonde equipment and/or changes of the evaluation algorithms. In Bremer $(1998,2001)$ some examples of such disturbances can be found. Therefore, the quality of ionosonde data sets have to be carefully controlled before trend analyses are carried out (Ulich et al., 2003). As long as we do not have final decisions about the quality of the ionosonde data sets we can only use mean or median values of all reasonable data sets, hoping that some errors of the derived individual trends may compensate each other.

\subsubsection{Scientific aspects}

What are the reasons of trends in the different layers of the ionosphere? At least two candidates are often discussed: anthropogenic pollution (e.g., $\mathrm{CO}_{2}, \mathrm{CH}_{4}, \mathrm{O}_{3}, \mathrm{H}_{2} \mathrm{O}, \ldots$ ) and geomagnetic trends.

To investigate the influence of an increasing atmospheric greenhouse effect the trends in the ionospheric $F 2$-, F1-, and E-regions can be compared with model calculations of Rishbeth (1990) and of Rishbeth and Roble (1992). Their theoretical results have been derived for a doubling of the atmospheric greenhouse gases $\mathrm{CO}_{2}$ and $\mathrm{CH}_{4}$. The effective change in greenhouse gases during the last 40 years where trends of the ionosonde data have mainly been investigated is about $20 \%$ (Brasseur and de Rudder, 1987; Houghton et al., 2001). Assuming a linear dependence between the content of the atmospheric greenhouse gases and the ionospheric effect, the experimental trends of table 5.II can be extrapolated to a level of doubled greenhouse gases. These values called $\mathrm{CO}_{2} * 2$ (exp) are compared with the corresponding model values $\mathrm{CO}_{2} * 2$ (mod) of Rishbeth (1990) and Rishbeth and Roble (1992) in table 5.III. 
Table 5.III. Mean experimental (exp) trends of different ionospheric parameters (from table 5.II) and expected changes of these data assuming a doubling of the atmospheric greenhouse gases $\left(\mathrm{CO}_{2} * 2\right)$. The model data (mod) are from Rishbeth (1990) and Rishbeth and Roble (1992).

\begin{tabular}{|c|c|c|c|c|}
\hline & Parameter & Mean exp trend & $\mathrm{CO}_{2} * 2(\exp )$ & $\mathrm{CO}_{2} * 2(\mathrm{mod})$ \\
\hline F2-region & $\begin{array}{l}f o F 2 \\
h m F 2\end{array}$ & $\begin{array}{c}-0.0018 \mathrm{MHz} / \mathrm{yr} \\
-0.009 \mathrm{~km} / \mathrm{yr}\end{array}$ & $\begin{array}{c}-0.36 \mathrm{MHz} \\
-1.8 \mathrm{~km}\end{array}$ & $\begin{array}{c}-0.2 \ldots-0.5 \mathrm{MHz} \\
-10 \ldots-20 \mathrm{~km}\end{array}$ \\
\hline F1-region & foF 1 & $0.0027 \mathrm{MHz} / \mathrm{yr}$ & $0.54 \mathrm{MHz}$ & $0.3 \ldots 0.5 \mathrm{MHz}$ \\
\hline$E$-region & $\begin{array}{l}f o E \\
h^{\prime} E\end{array}$ & $\begin{array}{l}0.0014 \mathrm{MHz} / \mathrm{yr} \\
-0.040 \mathrm{~km} / \mathrm{yr}\end{array}$ & $\begin{array}{l}0.28 \mathrm{MHz} \\
-8.0 \mathrm{~km}\end{array}$ & $\begin{array}{c}0.05 \ldots 0.08 \mathrm{MHz} \\
-2.5 \mathrm{~km}\end{array}$ \\
\hline
\end{tabular}

\subsubsection{F2-region}

The agreement between the experimental and model trends in $f o F 2$ and $h m F 2$ seems to be quite reasonable looking at the data in table 5.III. However, the differences between the individual trends in foF 2 and $h m F 2$ at different stations are very strong, and the derived mean trends are not statistically significant different from zero as can be seen in table 5.II. Therefore, the agreement between model and experimental data is accidental. The reason for the strong variability in the F2-region is not quite clear. After fig. 5.5 there seem to be regional differences which could be caused by dynamical effects in the plasma of the F2-region. Such strong regional differences of the $h m F 2$ trends were also detected earlier by other authors using a more limited data volume (Ulich and Turunen, 1997b; Bencze at al., 1998; Bremer, 1998). From satellite observations (Keating et al., 2000) it is known that the observed long-term neutral density reduction near $350 \mathrm{~km}$ altitude is in good agreement with model calculations of an increasing greenhouse effect (Akmaev, 2002). That means that the possible greenhouse effect in ionospheric data series is superposed by unknown dynamical processes which are more important for the variability of the ionized component than for the neutral gas at F2-region heights.

Using differences of $h m F 2-h{ }^{\prime} F$ Bencze (2002) derived long-term trends which contain information about the plasma temperature of the lower part of the F2-region. For most of the used 20 European stations a negative trend was detected in qualitative agreement with an expected cooling of the atmosphere due to an increasing atmospheric greenhouse effect.

With the method developed by Mikhailov and Marin $(2000,2001)$ the estimated trends in foF 2 and $h m F 2$ are explained by the remaining influence of geomagnetic activity (geomagnetic control concept). After their investigations their derived trends depending on local time and latitude can be explained by long-term variations of geomagnetic activity.

With a revised method Mikhailov et al. (2002) tried to remove this geomagnetic influence. The remaining relative trend in $f_{O F} 2$ noon values for the station Slough with $-2.210^{-4}$ year $^{-1}$ can be converted to a mean trend of $-0.0022 \mathrm{MHz} / \mathrm{yr}$ if a mean $f o F 2$ value of $10 \mathrm{MHz}$ is assumed. This trend value agrees well with the mean global trend for $f_{O F} 2$ in table 5.II and is thus in reasonable agreement with the model value in table 5.III. Therefore, this $f o F 2$ trend can be explained by an increasing greenhouse effect. However, an influence of the very long-lasting increase of the geomagnetic activity, as found in long-term variations of the geomagnetic aa index during the last century (Clilverd et al., 1998; Gulyaeva, 2002), on trends in $f o F 2$ should also lead to a negative foF2-trend due to the negative correlation between trends in geomagnetic activity and foF 2 after the geomagnetic control concept.

Alfonsi et al. (2002a,b) tried to remove the influence of geomagnetic activity on foF 2 -trends by using only geomagnetically quiet hourly data in their analyses. Their mean foF2-trend derived from 4 different stations (see fig. 5.6) with $-0.0035 \mathrm{MHz} / \mathrm{yr}$ is slightly stronger but not very different from the expectations after the greenhouse effect. 
Danilov $(2002,2003)$ used quite another method to derive non-geomagnetic trends in foF 2 . His mean trend, derived from 23 different stations, is with $-0.012 \mathrm{MHz} / \mathrm{yr}$ also negative but markedly stronger than the trends in table 5.II as well as those from Mikhailov et al. (2002) and Alfonsi et al. (2002a,b). But such differences are not very surprising if we remember the strong variability between the trends detected at different stations and the fact that these authors used different stations in their analyses.

\subsubsection{F1-region}

The agreement of the mean experimental trend in the F1-region (described in Section 5.3.2) with model trends in table 5.III is surprisingly good. Therefore, the global foF1-trend can be explained by an increasing atmospheric greenhouse effect.

\subsubsection{3. $E$-region}

As seen from table 5.III, in the E-region the experimental and theoretical trend values agree qualitatively with a lowering of the height $h^{\prime} E$ and an increase in $f o E$. However the experimental trends are markedly stronger than the model values. The derived positive $f o E$ trend is also in general agreement with rocket mass spectrometer measurements of the ion density ratio $\left[\mathrm{NO}^{+}\right] /\left[\mathrm{O}_{2}^{+}\right]$in the $E$-region (Danilov and Smirnova, 1997). The observed negative trends of $\left[\mathrm{NO}^{+}\right] /\left[\mathrm{O}_{2}{ }^{+}\right]$cause increasing electron densities and therefore increasing $f o E$ values as the dissociative recombination coefficient of $\mathrm{NO}^{+}$is markedly larger than that of $\mathrm{O}_{2}{ }^{+}$.

For years after 1970 Mikhailov and de la Morena (2003) also found with their revised trend method increasing foE values, a quantitative comparison with the model trends in table 5.III is however impossible. Nevertheless they propose an increasing chemical pollution due to an increasing number of rocket launchings and/or an increasing atmospheric greenhouse effect to explain the observed $f_{O E}$ increase.

\subsubsection{4. $D$-region}

The shrinking of the lower ionosphere as derived from LF reflection height observations (fig. 5.12) can be explained by a cooling of the strato- and mesosphere as expected from an increasing atmospheric greenhouse effect (Bremer and Berger, 2002). The estimated amount of the atmospheric cooling depends however also on possible changes in the density of nitric oxide $n_{\mathrm{NO}}$ and of the effective recombination coefficient $\alpha_{\text {eff }}$ near the reflection height of about 82 $\mathrm{km}$. Unfortunately there are no experimental data of long-term changes in these two quantities, however there exist model results which predict a decrease of $n_{\mathrm{NO}}$ (Roble and Dickinson, 1989; Beig, 2000) and an increase in $\alpha_{\text {eff }}$ in the mesosphere (Chakrabarty, 1997; Beig, 2000). As shown by Bremer and Laštovička (2002) and Bremer (2003) a common interpretation of the trends of the LF reflection heights and of the absorption data at different frequencies is only possible if the trends in $n_{\mathrm{NO}}$ and $\alpha_{\text {eff }}$ as predicted from model calculations are taken into consideration. The mesospheric temperature trends derived from the trends in LF reflection heights and ionospheric absorption data are in reasonable agreement with other experimental trends derived from longterm lidar and rocket measurements (Bremer, 2003). As shown by model results (Bremer and Berger, 2002; Bremer, 2003) the experimental temperature trends can qualitatively be explained by an increasing atmospheric greenhouse effect. The experimental trends are however stronger than the model results. 


\subsection{Summary AND CONCLUSIONS}

Using data of reflection height observations in the LF range and ionospheric absorption measurements in the LF, MF, and HF ranges for trend analyses in the $D$-region as well as data of ionosonde observations for trend estimations in the $E$-, $F 1$-, and $F 2$-regions, the following short summary and conclusions can be given:

General aspects

- Long-term ionospheric data series have to be carefully checked concerning their homogeneity. Discontinuities caused by different technical changes can markedly disturb the results of trend analyses.

- The solar and geomagnetically induced variations of most ionospheric parameters are essentially stronger than the long-term trends and have carefully to be eliminated in trend analyses.

F2-region

- The mean global trends are unimportant for practical ionospheric prediction models. In such models the solar and geomagnetic variability are the most important external factors.

- Due to a wide variability of the individual trends in the $F 2$-region no significant global trends could be derived for foF 2 and $h m F 2$. Therefore, the relatively reasonable agreement between the mean global experimental and model results could be accidental. The regional differences of the trends hint at an unknown dynamical process which superposes a possible greenhouse effect in the F2-region.

- Using different $h m F 2-h^{\prime} F$ however a general cooling of the lower part of the $F 2$-region could be derived in qualitative agreement with the greenhouse effect.

- The derived trends after the geomagnetic control concept contain geomagnetically induced components causing typical local time and latitudinal trend variations.

- Different approaches to eliminate geomagnetic activity changes lead to negative foF 2 -trends as proposed by model results of an atmospheric greenhouse effect. The experimental trends are however slightly stronger than the model predictions. If the geomagnetic influence could not be totally removed, then these negative trends could also be explained by the very long-term increase in geomagnetic activity.

\section{F1-region}

- The mean global trend in the $F 1$-region (increase in $f o F 1$ ) agrees quite well with model results of an increasing greenhouse effect.

\section{E-region}

- The mean global trends in the $E$-region (lowering of $h^{\prime} E$, increase of $f o E$ ) are in qualitative agreement with other experimental results and with model results of an increasing greenhouse effect. However, the experimental trends are stronger than the model results.

- Investigations with a revised trend method lead to an $f o E$-increase after about 1970.

\section{D-region}

- The trends in the $D$-region (lowering of reflection heights and different trends in ionospheric absorption in dependence on frequency of the measuring path) can qualitatively be explained by an increasing atmospheric greenhouse effect. The experimental trends are however stronger than expected from model results.

Summarizing, the investigation of ionospheric trends is an important task for the understanding of structure and dynamics of the ionosphere in general and for the derivation of anthropogenic influ- 
ences in particular. Combined experimental trend analyses (including quality control of existing data series as well as introduction of additional data sets) and model activities are necessary for future trend investigations.

\section{ACKNOWLEDGEMENTS}

The investigations presented here were mainly carried out in the COST 271 project «Effects of the upper atmosphere on terrestrial and Earth-space communications (EACOS)». The authors are very grateful to all participants who took actively part in the analysis of trends in the Earth's atmosphere and ionosphere: P.S. Cannon, U.K.; G. De Franceschi, Italy; T. Gulyaeva, Russia; C.M. Hall, Norway; M. Materassi, Italy; B. de la Morena, Spain, L. Perrone, Italy; A. Poole, South Africa; G. Sole, Spain; Th. Ulich, Finland.

The authors thank R. Conkright of the NGDC, Boulder, U.S.A., the U.K. ionosonde group, the World Data Centre C-1, the IPS (Australia) and IRF (Sweden) for providing ionosonde data.

\section{REFERENCES}

AKMAEV, R.A. (2002): Modeling of the cooling due to $\mathrm{CO}_{2}$ increases in the mesosphere and lower thermosphere, Phys. Chem. Earth, 27, 521-528.

Alfonsi, L., G. De Franceschi and L. Perrone (2001): Long term trend in the high latitude ionosphere, Phys. Chem. Earth, 26, 303-307.

Alfonsi, L., G. De Franceschi, L. Perrone and M. Materassi (2002a): Long-term trends of the critical frequency of the F2-layer at northern and southern high latitude regions, Phys. Chem. Earth, 27, 607-612.

Alfonsi L., G. De Franceschi, L. Perrone and C. Scotto (2002b): Long-term trends of the ionosphere at mid and high latitude regions, in Proceedings URSI, August 2002, Maastricht, The Netherlands.

BEIG, G. (2000): The relative importance of solar activity and anthropogenic influences on the ion composition, temperature, and associated neutrals of the middle atmosphere, J. Geophys. Res., 105, 19841-19856.

BENCZE, P. (2002): Some results referring to the long-term change of ionospheric parameters, Acta Geod. Geophys. Hung., 37 (4), 403-408.

Bencze, P., G. Sole, L.F. Alberca and A. Poole (1998): Long-term changes of hmF2: possible latitudinal and regional variations, in Proceedings of the 2nd COST 251 Workshop (RAL U.K.), 3031 March 1998, Side, Turkey, 107-113.

BilitZA, D. (2002): Ionospheric models for radio propagation studies, Review of Radio Sciences, edited by W.R. STONE (IEEE and Wiley), 625-679.

Brasseur, G. and A. DE RudDER (1987): The potential impact on atmospheric ozone and temperature of increasing trace gas concentrations, J. Geophys. Res., 92, 10903-10920.

Bremer, J. (1992): Ionospheric trends in mid-latitudes as a possible indicator of the atmospheric greenhouse effect, J. Atmos. Terr. Phys., 54, 1505-1511.

Bremer, J. (1998): Trends in the ionospheric $E$ - and $F$-regions over Europe, Ann. Geophysicae, 16, 986-996.

Bremer, J. (2001): Trends in the thermosphere derived from global ionosonde observations, $A d v$. Space Res., 28 (7), 997-1006.

BREMER, J. (2003): Mesospheric temperature trends at mid-latitudes derived from LF radio propagation experiments, Adv. Space Res., 32 (9), 1653-1662.

Bremer, J. and U. BERGER (2002): Mesospheric temperature trends derived from ground-based LF 
phase-height observations at mid-latitudes: comparison with model simulations, J. Atmos. SolarTerr. Phys., 64, 805-816.

BREMER, J. and J. LAŠTOVIČKA (2002): Trends in the ionospheric $D$ - and $E$-regions using results of different radio propagation experiments, in Proceedings of the 2nd COST 271 Workshop, 2-4 October 2002, Faro, Portugal.

CCIR (1966): CCIR Atlas of Ionospheric Characteristics (CCIR, Geneva).

Chakrabarty, D.K. (1997): Mesopause scenario on doubling of $\mathrm{CO}_{2}$, Adv. Space Res., 20 (11), 2117-2125.

Clilverd, M.A., T.D.G. Clark, E. Clarke and H. Rishbeth (1998): Increased magnetic storm activity from 1868 to 1995, J. Atmos. Solar-Terr. Phys., 60, 1047-1056.

DANILOV, A.D. (2002): The method of determination of the long-term trends in the F2-region independent of geomagnetic activity, Ann. Geophysicae, 20, 511-521.

DANILOV, A.D. (2003): Long-term trends of foF 2 independent of geomagnetic activity, Ann. Geophysicae, 21, 1167-1176.

DaniLOv, A.D. and N.V. Smirnova (1997): Long-term trends in the ion composition of the E-region, Geomagn. Aeron., 37 (4), 35-40 (in Russian).

De Franceschi, G., T.L. Gulyaeva, L. Perrone and B. Zolesi (1999): MAC: an oriented Magnetic Activity Catalogue for ionospheric applications, URSI IRI Newsl., 6 (4), 5-6.

De Franceschi, G., T.L. Gulyaeva, L. Perrone and B. Zolesi (2002): A statistical analysis of ionospheric irregularities at mid and high latitudes, Inverse Problems, 18, 67-78.

DUDENEY, J.R. (1983): An improved model of electron concentration with height in the ionosphere, J. Atmos. Terr. Phys., 45, 629-640.

Gulyaeva, T. (2002): Forecast of recurrent magnetic storms with a one-day lead time, Geomagn. Aeron., 42, 159-164 (in Russian).

HALL, C.M. and P.S. CANNON (2001): Indication of the shrinking atmosphere above Troms $\emptyset\left(69^{\circ} \mathrm{N}\right.$, $19^{\circ}$ E), Atmos. Sci. Lett., R. Meteorol. Soc., doi10.1006/asle.2001.0036.

Hall, C.M. and P.S. CANNON (2002): Trends in foF 2 above Troms $\emptyset\left(69^{\circ} \mathrm{N}-19^{\circ} \mathrm{E}\right)$, Geophys. Res. Lett., 29 (23), 2128, doi:10.1029/2002GL016259.

Hall, C.M. and T.L. Hansen (2003): 20th century operation of the Tromsø ionosonde, Adv. Polar Upper Atmos. Res., 17, 155-166.

Houghton, J.T., Y. Ding, D.J. Groggs, M. Noguer, P.J. van Der Linden, X. Dai, K. Maskell and C.A. Johnson (2001): Climate change: the scientific basis, in Contribution of WG 1 to the $3 r d$ Assessment Report of the IPCC (Cambridge University Press).

JoNES, W.B., R.P. GRAHAM and M. LEFTIN (1969): Advances in ionospheric mapping by numerical methods, ESSA, US Government Printing Office, Washington DC.

KEATING, G.M., R.H. TOLSON and M.S. BRADFORD (2000): Evidence of long term global decline in the Earth's thermospheric densities apparently related to anthropogenic effects, Geophys. Res. Lett., 27, 1523-1526.

KÜRSCHNER, D. and CH. JACOBI (2002): Trends and periodicities in nighttime LF radio wave reflection heights, Paper presented at the 27th General Assembly EGS, Symposium ST11, Nice.

LAŠTOVIČKA, J. (2001): Long-term trends in the lower ionosphere, Adv. Space Res., 28 (7), 10071016.

LAŠTOvIČKA, J. (2002): Long-term changes and trends in the lower ionosphere, Phys. Chem. Earth, 27, 497-507.

LAŠTOVIČKA, J. and J. BREMER (2004): An overview of long-term trends in the lower ionosphere below 120 km, Surv. Geophys., 25, 69-99.

LAŠTOVIČKA, J. and D. PANCHEVA (1999): Trends in the characteristics of the annual and semiannual variations observed in the radio wave absorption in the lower ionosphere, Ann. Geophysicae, 17, 1336-1343.

Marin, D., A.V. Mikhailov, B.A. De la Morena and M. Herraiz (2001): Long-term $h m F 2$ trends 
in the Eurasian longitudinal sector from ground-based ionosonde observations, Ann. Geophysicae, 19, 761-772.

Mikhailov, A.V. and B.A. DE LA MorenA (2003): Long-term trends of foE and geomagnetic activity variations, Ann. Geophysicae, 21, 751-760.

Mikhailov, A.V. and D. MARIN (2000): Geomagnetic control of the foF 2 long-term trends, Ann. Geophysicae, 18, 653-665.

Mikhailov, A.V. and D. MARIN (2001): An interpretation of the foF2 and $h m F 2$ long-term trends in the framework of the geomagnetic control concept, Ann. Geophysicae, 19, 733-748.

Mikhailov, A.V., V.V. Mikhailov and M.G. Skoblin (1996): Monthly median foF2 and M(3000)F2 ionospheric model over Europe, Ann. Geofis., XXXIX (4), 791-805.

Mikhailov, A.V., D. Marin, T.Yu. Leschinskaya and M. Herraiz (2002): A revised approach to the foF 2 long-term trend analysis, Ann. Geophysicae, 20, 1663-1675.

Nestorov, G., D. Pancheva and A.D. Danilov (1991): Climatic changes of ionospheric absorption of radio waves in the LF range, Geomagn. Aeron., 31, 1070-1073 (in Russian).

Perrone, L. and G. De Franceschi (1999): A correlation study between time-weighted geomagnetic indices and high latitude ionosphere, Phys. Chem. Earth, 24, 389-392.

Rishbeth, H. (1990): A greenhouse effect in the ionosphere?, Planet. Space Sci., 38, 945-948.

Rishbeth, H. and R.G. Roble (1992): Cooling of the upper atmosphere by enhanced greenhouse gases - Modelling of the thermospheric and ionospheric effects, Planet. Space Sci., 40, 1011-1026.

Roble, R.G. and R.E. Dickinson (1989): How will changes of carbon dioxide and methane modify the mean structure of the mesosphere and thermosphere?, Geophys. Res. Lett., 16, 1441-1444.

Rogers, N., P. CANNON and C. Hall (2002): Practical implications of long term trends in the critical frequency and the height of the F2-layer above Troms $\varnothing\left(70^{\circ} \mathrm{N}, 19^{\circ} \mathrm{E}\right)$, in Proceedings of the $2 n d$ COST 271 Workshop, 2-4 October 2002, Faro, Portugal.

Rush, C., M. Fox, D. Bilitza, K. Davies, L. F. McNamara, F. Stewart and M. Pokempner (1989): Ionospheric Mapping - An update of foF2 coefficients, Telecom J., 56, 179-182.

SHIMAZAKI, T. (1955): World wide daily variations in the height of the maximum electron density in the ionospheric F2-layer, J. Radio Res. Labs., Japan, 2, 85-97.

Taubenheim, J. (1969): Statistische Auswertung geophysikalischer und meteorologischer Daten, Akad. Verlagsgesellschaft Geest und Portig K.-G., Leipzig.

Ulich, TH. (2000): Solar variability and long-term trends in the atmosphere, Sodankylä Geophysical Observatory Publications No. 87, Oulu.

Ulich, Th. and E. Turunen (1997a): Evidence for long-term cooling of the upper atmosphere in ionospheric data, Geophys. Res. Lett., 24, 1103-1106.

ULICH, TH. and E. TURUNEN (1997b): Long-term behaviour of ionospheric F2-layer peak height on a global scale, paper presented at Session 2.18 of the 8th Scientific Assembly of IAGA, Uppsala.

Ulich, Th., M.A. Clilverd and H. Rishbeth (2003): Determining the long term change in the ionosphere, EOS Trans. Am. Geophys. Un., 84 (52), 581-585.

WrenN, G.L. (1987): Time-weighted accumulations $A p(\tau)$ and $K p(\tau)$, J. Geophys. Res., 92, 125-129. 